\title{
INTRAMEDULLARY HAEMANGIOBLASTOMA OF THE SPINAL CORD ASSOCIATED WITH PIAL VARICOSITIES SIMULATING INTRADURAL ANGIOMA
}

\author{
BY \\ K. R. KRISHNAN and W. THOMAS SMITH \\ From the Queen Elizabeth Hospital, Birmingham, and the Department of Pathology, \\ University of Birmingham
}

Intramedullary haemangioblastoma of the spinal cord may be associated with overlying pial varicosities. Wyburn-Mason (1943) referred to 10 cases in the literature and added four of his own. The degree of development of the varicosities is variable but occasionally the cord is completely obscured by abnormal vessels which may give rise to the radiological and operative appearances of intradural venous angioma (Black and Faber, 1935; WyburnMason, cases 53 and 55; Craig and Horrax, 1949). The following case of this type is of practical interest in view of a recent suggestion that more attempts should be made to remove spinal intradural angiomas in order to lessen the dangers of haemorrhage and of cord compression and degeneration (Shephard, 1960).

\section{Case Report}

A woman aged 40 was referred to the Neurosurgical Department of the Queen Elizabeth Hospital, Birmingham, in December, 1954, complaining of lumbar pain and paraesthesia, numbness of the left leg, dragging of the left foot while walking, and difficulty in starting micturition. The pain and paraesthesia had been present for seven years and the other symptoms for about two years. Before this she had been in sound health. There was no family history of any similar complaint or of any congenital abnormality.

On examination there was mild spasticity of both lower limbs, bilateral ankle clonus with extensor plantar responses, and sensory loss to pinprick over segments T6 to $\mathrm{L} 1$ on both sides and over segments L4 to S1 on the left. Lumbar puncture showed a subarachnoid block and the cerebrospinal fluid protein level was $430 \mathrm{mg} . / 100 \mathrm{ml}$. Plain radiographs of the spine revealed erosion of the pedicles of the sixth to ninth thoracic vertebrae. Lumbar myelography (using Myodil) showed a long stretch of tortuous vessels outlined by a thin film of contrast medium above the level of T10 and cisternal myelography indicated that the upper limit of the lesion was at T5. A diagnosis of intradural angioma was made, effective excision was considered impractical, and the patient left hospital.
She was re-admitted in May 1960 with complete motor is and sensory paraplegia below T10, root pains in segments T8 and T9 on the left, painful flexor spasms, and a distended bladder with dribbling incontinence. Laminectomy was performed exposing segments T6 to T9. A large intradural angiomatous malformation extended upwards, downwards, and laterally beyond the limits of the operative exposure. In an effort to abolish the root pains the left seventh and eighth thoracic sensory roots were exposed and divided, a difficult procedure as they wero enveloped in a thick sheath of enlarged vessels. A weet later $0.7 \mathrm{ml}$. of phenol was injected intrathecally as thథ flexor spasms were still troublesome. After this the spasms were much improved and the patient was able tQ return home.

She was again admitted in a very much worse state in October 1960 and an attempt was made to excise the lesion. The old laminectomy wound was re-opened ane extended to expose segments T4 to T11. The cord was hidden by abundant enlarged and tortuous vessels which extended from the top to the bottom of the exposure, through the intervertebral foramina, and laterally as far as could be seen. Troublesome bleeding was encountered on attempting to define the main vessels and as excision was clearly technically impossible the operation was abandoned.

Post-operatively the patient had an exacerbation of her urinary tract infection and developed severe bronchopneumonia despite active antibiotic therapy. She died three days after the operation from respiratory failure.

Pathological Findings.-Permission was granted only for examination of the spinal cord, which was removed from C3 to L5. Beneath the dura the dorsal and lateral surfaces of the cord between T2 and L2 were covered with a plexiform conglomeration of blood vessels resembling a venous angioma (angioma racemosum venosum). These blood vessels, which gradually became less numerous towards the upper and lower limits of the lesion, were in places obscured by adherent blood clot and gelatin sponge (Fig. 1). Segments T7 and T8 were firm $D$ and enlarged. Their cut surfaces $(1.7 \times 1.4 \mathrm{~cm}$.) were reddish-brown and flecked with irregular yellow areas; dilated blood vessels extended into the cord tissue and $O$ the normal markings were not recognizable (Fig. 2B). 


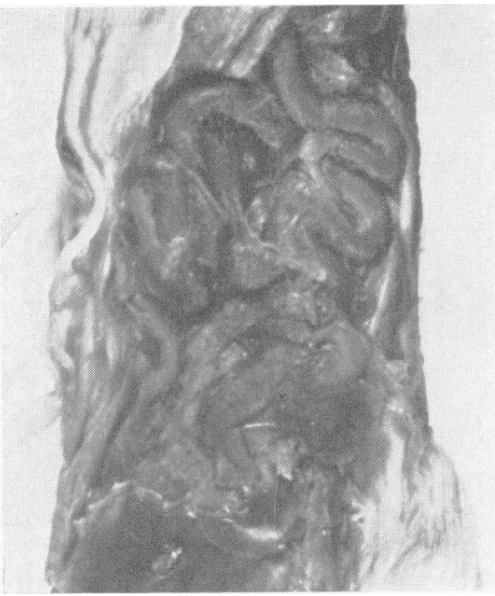

FIG. 1

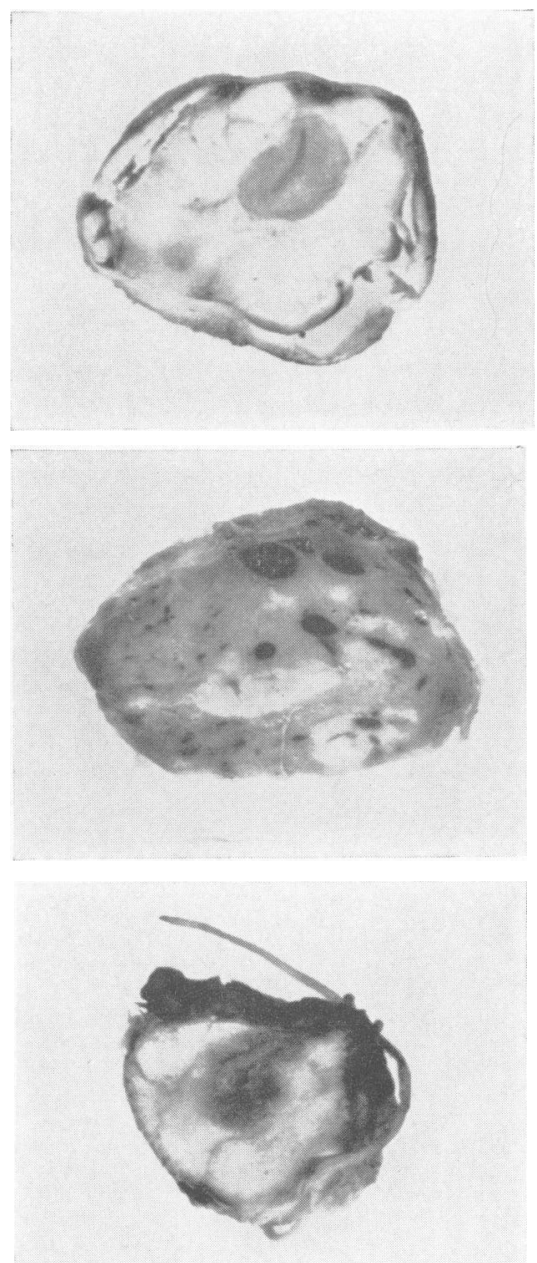

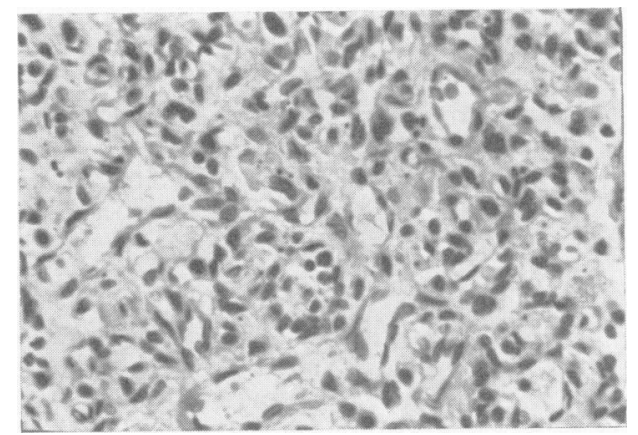

FIG. 3

FIG. 2A

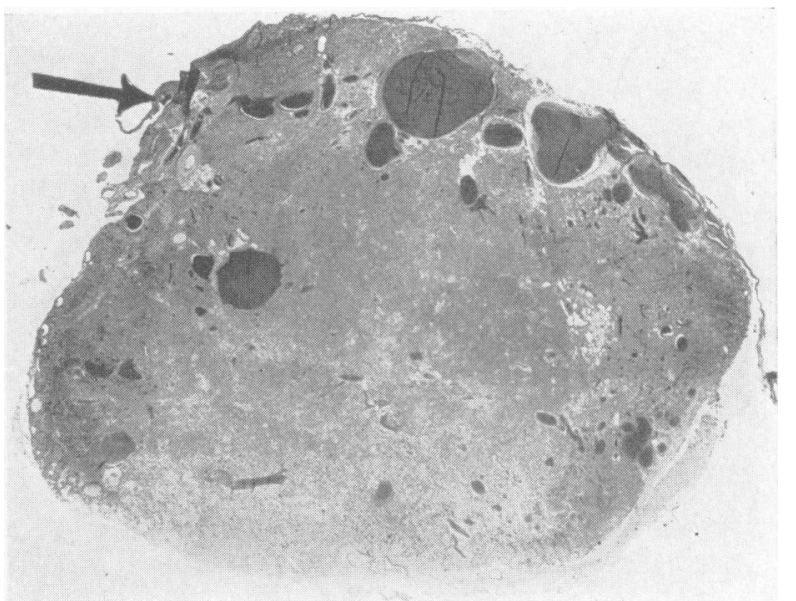

FIG. 4

FIG. 2B

FIG. 1,-Dorsal surface of spinal cord at T7 - 8 showing dilated pial veins obscured by gelatin sponge and blood clot in the upper part of the figure.

Fig. 2. $-A=C 8 \quad B=T 8 . \quad C=: T 11$. Showing syrinx at $C 8$ and T11, tumour at T8, and dorsal pial varices at T8 and T11.

Fig. 3.-T7. Haemangioblastoma. Haematoxylin and eosin $\times 250$.

Fig. 4.-T7. Haemangioblastomatous infiltration replacing normal markings of cord. Note dilated veins. Collapsed veins arrowed. Haematoxylin and eosin $\times 4 \cdot 5$. 
Segments T6 and T9 were shrunken and showed focal softenings. Throughout the rest of the cord in relation to the midline of the dorsal columns was an ovoid, grey area with a central slit-like cavity (Fig. 2A and C).

Histology.- In the enlarged seventh and eighth thoracic segments the normal cord structure is completely replaced by haemangioblastomatous tumour consisting of a network of capillaries, lined by swollen endothelium, and separated by polyhedral stromal cells (Fig. 3) which in some areas are vacuolated and contain sudanophile lipid. The capillaries have a prominent reticulin basement membrane and in places are dilated into larger sinuses. Reticulin fibres enclose and separate the majority of the stromal cells, the nuclei of which sometimes show hypertrophy, hyperchromatism, and/or reduplication.

The conglomeration of surface blood vessels extending from T2 to L2 is composed of dilated pial veins which are most numerous over the tumour and the adjacent shrunken segments, where they also extend into the cord substance (Fig. 4). At the operation site a few pial veins are thrombosed and others are collapsed and covered with gelatin sponge.

The shrunken segments (T6 and T9) adjacent to the tumour show diffuse gliosis and demyelination and areas of recent infarction.

The grey area in the dorsal columns throughout the rest of the cord is a syringomyelic cavity which contains serous fluid and has a dense wall of astrocytic glia in which Rosenthal fibres (see Grcevic and Yates, 1957) are abundant. It is dorsal to the central canal and its relation to the median fissure varies slightly between segments. In places the syrinx involves the dorsal and to a lesser extent the anterior horns, both of which show loss and degeneration of nerve cells and fibres. In the vicinity of the shrunken segments the syrinx loses its cavity and appears in sections as a solid glial trabecula, which divides into two parts before merging with the gliotic segments above and below the tumour.

\section{Discussion}

Venous dilatation over a haemangioblastoma of the spinal cord is not unusual but complete covering of the cord by abnormal vessels probably occurs in only a minority of cases. It may be suspected, however, that in the past some lesions described as intradural angiomas from the operative appearances may have been associated with an intramedullary tumour. The cause of the varicosities is obscure: it has been suggested that they are either a secondary result of the tumour or an associated developmental abnormality. According to Wyburn-Mason (1943) varicosities are practically unknown with other varieties of spinal tumour and also with syringomyelia alone.
The association of syringomyelia with haemangioblastoma and other types of intramedullary tumours of the cord is well recognized. The origin of the syrinx in such cases has frequently been discussed (e.g., Russell, 1932; Wyburn-Mason, 1943; Rand and Rand, 1960) and need not be considered here. Varicosities occur most often in those cases of haemangioblastoma in which syringomyelia is also present (Wyburn-Mason).

Before attempting to excise an intradural angioma the possibility that an intramedullary haemangioblastoma may also be present should be considered; operation is contraindicated if this is confirmed. Identification of an associated haemangioblastoma may be difficult. Myelography is not helpful. Ocular and other stigmata of Lindau-von Hippel disease suggest haemangioblastoma. According to Wyburn-Mason the cisternal fluid above an intrinsic haemangioblastoma is frequently xanthochromic and contains very large amounts of protein. But in some cases even operative exploration may fail to disclose the true nature of the condition.

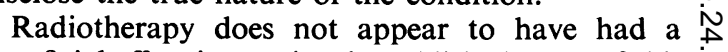
beneficial effect in previously published cases of this association.

\section{Summary}

Intrinsic haemangioblastoma of the spinal cor $\$$ is sometimes associated with extensive pial varico sities which result in the radiological and operativg appearances of intradural angioma.

This possibility should be remembered whes assessing the operability of an apparent spina angioma.

An illustrative case is described in which syringomyelia was also present.

We are grateful to Mr. Eric Turner for suggesting that we publish this case and for reading and criticising the manuscript.

\section{REFERENCES}

Black, W. C., and Faber, H. K. (1935). J. Amer. med. Ass., 104, 1889 .

Craig, W. McK., and Horrax, G. (1949). J. Neurosurg., 6, 518.

Grcevic, N., and Yates, P. O. (1957). J. Path. Bact., 73, 467.

Rand, R. W., and Rand, C. W. (1960). Intraspinal Tumors of Childhood. Thomas, Springfield, Illinois.

Russell, Dorothy S. (1932). J. Path. Bact., 35, 103.

Shephard, R. H. (1960). J. Neurol. Neurosurg. Psychiat., 23, 357.

Wyburn-Mason, R. (1943). The Vascular Abnormalities and Tumours of the Spinal Cord and its Membranes. Kimpton, London.

.

(1)

